\title{
Changes in Prosocial Motivation over Time: A Cross-Sector Analysis of Effects on Volunteering and Work Behavior
}

\author{
Alexander Kroll ${ }^{1} \&$ Dominik Vogel ${ }^{2}$ \\ ${ }^{1}$ Florida International University \\ ${ }^{2}$ University of Hamburg
}

This is an Accepted Manuscript of an article published by Taylor \& Francis Group in International Journal of Public Administration, 41(14) on 28/07/2017, available online: http://dx.doi.org/10.1080/01900692.2017.1347945

\begin{abstract}
A gap in research on prosocial motivation is that very little is known about its change across time, let alone, how such changes affect employee behavior. Using multiple waves of panel data, covering a period of sixteen years, this article finds that prosocial motivation is mostly stable, and there are no broader socialization effects in the private and public sector. However, when prosocial motivation increases, it leads to increases in either work or volunteering behavior, suggesting that public employees may use alternative outlets to realize their motivation if such motivational capital cannot be linked to the mission of their organizations.
\end{abstract}

Keywords: prosocial motivation; volunteering; work behavior; sector differences; panel data 


\section{Introduction}

Prosocial motivation is a concept that has become of major importance in public administration research (Perry, Hondeghem, \& Wise, 2010; Perry \& Wise, 1990). Employees who were found to be driven by altruism and other-orientation were also more likely to work in the public sector (Lewis \& Frank, 2002; Steijn, 2008; Wright \& Christensen, 2010), less dependent on utilitarian incentives (Bright, 2009; Rainey, 1982), and they performed better on the job if compared with other employees in the public service (Bellé, 2013; Vandenabeele, 2009). Though there is a growing literature that aims at further qualifying these observations (Christensen \& Wright, 2011; Moynihan \& Pandey, 2008; Steijn, 2008), one of the unanswered questions is whether prosocial motivation is a dynamic state or stable trait (Wright \& Grant, 2010). Such a distinction has critical implications because in the first case a prosocial motivation could be conceptualized as a personal disposition that varies over time and can be changed, whereas in the latter case it would be something static that only differs among people (Kjeldsen \& Jacobsen, 2013; Wright \& Christensen, 2010).

This article will address this topic comparing public- and private-sector employees. As previous studies suggest, a lot can be learned about public employees if one not only studies their motivation and behaviors but if there actually is a reference group to compare them with (Andersen, Pallesen, \& Pedersen, 2011; Christensen \& Wright, 2011). This comparison will help to broadly contrast publicand private-sector employees as well as tease out average sector effects, while it does not allow sorting out differences among similar occupations in both sectors (for such an approach, see Kjeldsen \& Jacobsen, 2013 or Kjeldsen, 2014).

The first part of the study will be devoted to explore the variation of prosocial motivation across time as a function of sector socialization. It will go beyond the expectation that employees in the public sector are likely to have stronger prosocial values than employees in the private sector due to attraction-selection effects and rather theorize about how these values might evolve over time. The two-sector design is particularly helpful here, because if socialization matters, then there should be different trends in both sectors. The analysis will reveal how stable or dynamic a prosocial motivation is over a longer period of time.

The second part of the article will take the analysis one step further and examine the behavioral effects of prosocial motivation (Perry, Brudney, Coursey, \& Littlepage, 2008; Wright, 2007). The behaviors under investigation are volunteering after hours and working overtime. Since performing both behaviors at the same time might create choices for public employees, the design of this study will make it possible to learn more about the nature of the effect of prosocial motivation. On the one hand, such motivational capital could be a "need" that loses some of its strength once it has found fulfillment through one outlet, suggesting that this motivation can be absorbed by a particular behavior. On the other hand, prosocial motivation may be a generic concept, which generally guides people's 
actions in various situations in life and which is capable of triggering several behaviors simultaneously. The two-sector design will be used again to determine how generic these effects are.

To address the two research questions outlined above, the study uses multiple waves of data from the German Socio-Economic Panel Study that covers a time period of sixteen years. It taps into the concept of prosocial motivation by tracking changes in two survey items - employees' care for others and their assessment of the importance of being socially and politically involved. The article finds that prosocial motivation is largely stable across time in both sectors, which is evidence against socialization effects. It also finds indication of the existence of absorption effects: increases in employees' prosocial motivation will either lead to extra effort being put in their public service work or in volunteering activities after hours. The article discusses the theoretical contribution of these results as well as their practical implications, such as that the recruitment of prosocially driven employees and the linkage of prosocial values to organizational missions is highly important to generate and utilize a workforce's motivational capital.

\section{Changes in Prosocial Motivation across Sectors}

What is prosocial motivation? The use of this concept in this article is in line with the sector-spanning understanding that "prosocial motivation is the desire to expend effort to benefit other people" (Grant, 2008, p. 49). This makes the concept different from extrinsic motivation, a type of motivation driven by task-external rewards like money, prestige, or job security. Further, the definition that is used here distinguishes prosocial motivation from intrinsic motivation which is driven by the interest in, and the enjoyment of, one's work (Gagné \& Deci, 2005; Grant, 2008) or attached feelings of accomplishment, self-esteem, and self-actualization (Cook, Hepworth, Wall, \& Warr, 1981). Prosocial motivation shares a great deal of similarities with the concept of public service motivation since both types of motivation belong to the category of "other orientation." Public service motivation has been characterized as a sub-dimension of prosocial motivation, where altruism is particularly "animated by specific dispositions and values arising from public institutions and missions" (Perry et al., 2010, p. 682).

There is overwhelming evidence that prosocial motivation occurs in the public as well as the private sector and that - on average - public employees are more prosocially driven than employees in the private sector (e.g., Christensen \& Wright, 2011; Lewis \& Frank, 2002; Steijn, 2008; Tschirhart, 1998). Little is known about how this motivation changes across time and whether one can expect different patterns in the public and private sector. This section identifies four arguments in the literature why, when using a longitudinal perspective, people's prosocial motivation should be a dynamic state rather than a stable trait.

First, prosocial motivation has been found to covary with organizational factors, such as red tape or leadership, suggesting that these factors can cause changes 
in a person's motivation (Moynihan \& Pandey, 2007; Wright, Moynihan, \& Pandey, 2012). However, it might be equally plausible that these differences in motivation are the results of selection effects, not of changes across time: prosocially motivated employees might be more likely to select into organizations with less red tape and more transformation leadership. Second, older employees have been found to have higher levels of prosocial motivation, pointing towards a life-cycle explanation of motivational change, where increasing life experience and social capital can be associated with stronger prosocial values (Anderfuhren-Biget, 2012; Leisink \& Steijn, 2008; Pandey \& Stazyk, 2008). An alternative explanation of this observation would be the existence of cohort effects and differences among generations as opposed to the effect of getting older. Third, motivationcrowding theory has shown that extrinsic incentives can decrease employee motivation, providing evidence for the hypothesis that there can be motivational change (Jacobsen, Hvitved, \& Andersen, 2014). A limitation of this research is that designs often were merely cross-sectional and that there is more evidence for the crowding out of intrinsic rather than prosocial motivation (Frey \& Jegen, 2001).

Fourth, the probably most compelling support for the idea of motivational change comes from three recent studies which have used longitudinal data, covering periods of six months, three years, and eight years. Kjeldsen and Jacobsen (2013) find that studentts' prosocial motivation declined after joining the workforce, and they report this effect to occur in both sectors. Ward (2014) finds a similar decrease in prosocial motivation but notes that participating in a national community service program first led to an increase in motivation. Brænder and Andersen (2013) report that soldiers' prosocial motivation changes due to their deployment to combat. These three studies suggest that prosocial motivation can vary, although one needs to keep in mind that all of them examined the impact of significant life changes, rather than simple adjustments in one's work environment. Cumulatively then, the four arguments provide convincing evidence as to why prosocial motivation is a dynamic state, though all of the presented findings are not without limitations.

H1: Employees' prosocial motivation is dynamic across time.

A second question the article addresses is, if prosocial motivation changes across time, are there different patterns in the public and private sector? The empirical literature on this subject is limited. As explained above, it is known that public employees show on average higher levels of prosocial motivation than their private-sector counterparts. What is unclear, though, is whether this is the result of selection (prosocially driven people select into public sector work) or socialization (public organizations reinforce prosocial values) (Wright \& Grant, 2010). In fact, a seminal study from the area of sociology suggests that there might be a little bit of both: Mortimer and Lorence (1979) show that graduates with strong a) extrinsic, b) social, or c) intrinsic values select into organizations characterized by a) high income, b) social content, or c) work autonomy. 
Ten years later, the values of people in each of the three categories were reinforced, which points towards the importance of the socialization effects of organizations in different sectors.

A study by Kjeldsen and Jacobsen (2013), which controls for people's profession, finds that levels of prosocial motivation decrease when graduates were confronted with the reality of work. However, this decrease was less severe for employees in public organizations, indicating a greater value congruence between prosocially driven people and public sector work. Overall, it is hypothesized that if employees spend most of their career serving the public, this will reinforce people's prosocial motivation. In contrast, the article proposes that private-sector work offers less opportunities to realize one's prosocial motivation and thus will curb related values.

$\mathrm{H} 2$ : The prosocial motivation of public sector employees increases across time.

H3: The prosocial motivation of private sector employees decreases across time.

Though most of the work on prosocial motivation suggests potential changes over time, there is also some support for the stability of this variable. Work, which has been subsumed under the label of the "impressionable years" hypothesis, points out that prosocial values, ideological attitudes, and partisan orientations change during adolescence but remain quite stable during a life time, just like other personality traits. Evidence is provided by several multi-year panel-data studies (Hatemi et al., 2009; Jennings \& Markus, 1984; Sears \& Funk, 1999). Similar claims have been made in the field of organizational behavior, where a meta-analysis of job satisfaction, a work-related attitude, shows that individual values remain largely constant across time, even after employees switched organizations (Dormann \& Zapf, 2001). The null hypothesis, therefore, is that there are no motivational changes over time and consequently no sectorspecific change patterns.

H0: Employees' prosocial motivation is stable across time.

\section{Prosocial Motivation, Volunteering, and Work Behavior}

This section theorizes about how changes in prosocial motivation affect volunteering and work behavior. Cross-sectional research has found positive effects, suggesting that public employees with stronger prosocial values are more likely to volunteer and to put more effort into their jobs. The longitudinal perspective of this study is different, in that it does not compare different employees with each other, but it studies changes in employees' prosocial values and related behavior over time. This allows learning more about the nature of the concept of prosocial motivation, as it gives the opportunity to examine whether increases in motivation will trigger volunteering and work behaviors simultaneously, or 
whether employees engage in some activities but not others. The article proposes that such an absorption of motivational capital is mainly a possibility for public employees for whom volunteering as well as the workplace offer competing opportunities to realize prosocial motivation. This is contrasted with the group of private sector employees for whom it is assumed to be unlikely that prosocial motivation will trigger work behaviors and who, instead, may focus on opportunities to volunteer.

Prior research has shown that there is a positive relationship between public employees' prosocial motivation and their work effort. On the one hand, they were found to be better at doing their assigned work compared with their colleagues (Vandenabeele, 2009), or their prosocial motivation moderated the performance effects of other person-related factors (Grant, 2008). On the other hand, these employees were also found to show higher levels of extra-role behavior which goes beyond normal job expectations and is usually not recognized by formal reward systems (Leisink \& Steijn, 2009; Wright, 2007). For example, some studies documented that prosocially driven employees are more likely to engage in organizational citizenship behavior, such as helping out their colleagues (e.g., Pandey, Wright, \& Moynihan, 2008). Other studies reported that these employees tend to take on extra responsibilities and engage in performance management practices which can create additional effort but might also be useful to improve outcomes for the clientele they serve (e.g., Kroll \& Vogel, 2014). The explanation behind these observations is straightforward. Employees with strong prosocial values put extra effort in their work in the public sector, because these jobs make it possible to do good for others and thus transform their motivation into action.

Another way of realizing prosocial motivation is not through public sector work but volunteering after hours. There is one stream of literature which has examined the role of prosocial motivation for volunteering behavior. For example, Perry et al. (2008) found that both concepts are positively related; though this relationship can be mediated by other factors (see also Lee, 2011). Further evidence of the motivation effect on the performance of charitable activities comes from Clerkin, Paynter, and Taylor (2009) who studied a sample of undergraduate students and Coursey, Brudney, Littlepage, and Perry (2011) who surveyed volunteer award winners.

Putting these findings together, the article assumes that prosocial motivation can foster different work-related behaviors in the public sector. That is, prosocially driven public employees will on the one hand be persistent at work and put in extra hours to be able to help others and serve their clientele. On the other hand, they will also engage in volunteering after hours. Thus, it can be hypothesized that prosocial motivation might be a generic concept that generally guides people's actions in various situations in life and which is capable of triggering several behaviors simultaneously.

$\mathrm{H}_{4}$ : Increases in prosocial motivation of public sector employees will foster their engagement in both volunteering and work behavior alike. 
However, the evidence presented above also allows for an alternative interpretation. Though prior research found many different examples of in-role and extra-role behaviors as well as volunteering that was triggered by employees' prosocial values, it is difficult to find studies that have examined the involvement in one behavior while controlling for the involvement in another. In other words, though it is quite likely that prosocial motivation fosters certain behaviors, it is still possible that employees choose to engage in one activity over another. For example, public employees who believe that they cannot realize their prosocial motivation through their job, let's say due to a lack of value congruence with the organization they work for (Moynihan \& Pandey, 2008), might use volunteering as an alternative outlet.

Such absorption effects would also be in line with Simon's (1959) assumption of bounded rationality. Since time, capacity, and motivation are not endless resources, this article hypothesizes that different activities will end up in a competition with each other and create choices. Thus, being persistent at work in a public sector job might already "absorb" an employee's prosocial motivation which would make it impossible to engage in volunteering activities with the same intensity. However, it is just as likely that volunteering may absorb employees' prosocial motivation, leaving them with less resources to do more at work. Prior research does not suggest a hierarchy of work and voluntary behaviors or in-role and extra-role behaviors more broadly (e.g., Grant \& Ashford, 2008). Organizational pressure may direct attention to in-role activities, while autonomy and enjoyment often associated with extra-role activities may make employees rather engage in this type of work. There is only scattered evidence indicating that in-role performance is a condition for extra-role performance (MacKenzie, Podsakoff, \& Ahearne, 1998).

Due to the lack of literature on employees' prioritization of in-role and extrarole activities, and more specifically public employees' prioritization of work behavior and volunteering, hypothesis $4 \mathrm{~b}$ is formulated somewhat open-ended as an "either ... or" proposition. This relationship is expected to be more straightforward for private sector employees. If their prosocial motivation increases, their work will offer them only few opportunities to realize this motivation, which is why they may engage in volunteering instead. However, one needs to acknowledge that there are also occupations in the private sector which may allow employees to make a difference in other people's life, but such opportunities are less common than in the public sector. In that sense, the public-private divide is in reality not as clear-cut as the theory would suggest, but the resulting statistical noise will disfavor the confirmation of the hypotheses which makes this somewhat simplified assumption a conservative one.

$\mathrm{H}_{4}$ : Increases in prosocial motivation of public sector employees will foster their engagement in either volunteering or work behavior.

H5: Increases in prosocial motivation of private sector employees will foster their engagement in volunteering, not work behavior. 


\section{Data and Methods}

\section{Sample}

This study uses data from the German Socio-Economic Panel Study (SOEP). ${ }^{1}$ Since 1984 , SOEP has been surveying a panel of people, annually tracking changes in socio-economics, income, or education. The survey's annual response rate is fairly high (90\%-94\%), and out of those who were a part of the panel in 1992 (the first wave) a vast majority of respondents (60\%-70\%, varying for different subgroups) could be retained until 2008 (the last wave). SOEP is comparable to the Panel Study of Income Dynamics (PSID) in the U.S. or the British Household Panel Survey (BHPS).

The questions relevant for this study were only asked in 1992, 1995, 2004, and 2008. Questions related to volunteering were only asked in three of these years, which is why the regression analysis is limited to data from 1992, 1995, and 2008, whereas the descriptive analysis of the prosocial motivation measures draws data from all four waves. To be able to study socialization effects in the public and private sector, the sample is restricted to those employees who consistently worked in one of the two sectors at all four study years. A balanced panel was created that excluded all observations with missing values on the dependent variables or the two prosocial motivation measures. As a result, the two generated data sets both span across a period of sixteen years. One consists of three data waves and 1,472 respondents (including 375 public employees), and the other consists of four waves and 1,332 respondents (including 345 public employees).

\section{Measures and Control Variables}

All measures can be found in the appendix. Two different dependent variables are used in this study. The first one is "volunteering," measured through a question about how often survey participants engage in volunteering activities in clubs, associations, or social services, and possible answers were "at least once a week" (4), "every month" (3), "less than once a month" (2), "never" (1). The second dependent variable captures respondents' work engagement by asking them about their self-reported hours of overtime per week. Overtime in the public sector in Germany is likely to be "prosocial" because it is mostly not financially rewarded (for $88.1 \%$ of the observations in the public sector, overtime was not financially compensated). And even if compensated, rewards for overtime are likely to be marginal one-time payments because they are not a systematically established element in the labor agreements governing public sector work at the

\footnotetext{
${ }^{1}$ The data of the German Socio-Economic Panel Study (SOEP) are collected and provided by the German Institute for Economic Research (DIW Berlin). For further details on the SOEP see Wagner, Frick, and Schupp (2007).
} 
federal, state, and local level. As will be explained below, the analyses control for paid versus unpaid overtime using a dummy variable.

In order to differentiate public from private sector employees one specific question is used. Respondents were asked whether they have a job in public administration. In Germany, all public-sector employees at the federal, state, and local level are subject to specific public-administration collective-bargaining agreements and payment schemes, which makes it easy to identify yourself as a public servant. To be better able to contrast public and private sector employees, the three branches education; health and social work; and activities of membership organizations were excluded from the private sector sample. This way one avoids miscounting nonprofit organizations into the private-sector sample. It is noteworthy that the traditional public-private divide is more prevalent in Germany than in other Western countries, with relatively few attempts to privatize or contract-out public services.

Prosocial motivation is measured using two items. Since both items were not highly correlated, they are treated as separate motivation variables. The first variable is "the importance of social and political involvement." This is not a behavioral measure but one that is used to pick up on a person's attitude towards social and political involvement. It is very similar to other measures of prosocial motivation, such as "it is important for me to contribute to the common good" (Kim et al., 2013) or "being useful to society" (Wright, Christensen, \& Pandey, 2013). The second item is "care for others," and respondents were asked how important it is for them to "be there for others." This measure taps into the core of prosocial motivation; it is the most widely used single-item measure of public service motivation, was found to be highly correlated with multi-item scales of public service motivation (Wright et al., 2013), and has been included in several indices measuring prosocial motivation (Grant, 2008; Kim et al., 2013; Perry, 1996).

The analyses control for several alternative explanations of changes in volunteering and work behavior (doing overtime) identified in prior research. The first variable is political interest which may have a positive effect on work behavior (for public employees, see vandenabeele, 2009) and volunteering (Bekkers, 2005). Though not a part of the prosocial motivation concept, "political interest" has been argued to be related to one particular sub-dimension of public service motivation - attraction to policy making - and is therefore a relevant control (Ritz, 2011). In addition, four job related variables are included (Moynihan \& Pandey, 2007; Vandenabeele, 2009): 1) job satisfaction which might have a positive effect on work behavior; 2) organizational tenure; 3 ) job prestige which is supposed to pick up on employees' publicly recognized status and to a certain extent their hierarchical position (prestige was measured using SOEP's magnitude prestige scale developed by Wegener (1992) and documented by Frietsch and Wirth (2001)); and as indicated above 4) a dummy variable capturing if respondents are fully or partly paid for their overtime. 
Table 1: Descriptive Statistics and Correlations

\begin{tabular}{|c|c|c|c|c|c|c|c|c|c|c|c|c|c|}
\hline & mean & S.D. & range & (1) & (2) & (3) & (4) & (5) & (6) & (7) & (8) & (9) & (10) \\
\hline (1) Overtime & 2.03 & 3.52 & $0-23.1$ & 1.00 & & & & & & & & & \\
\hline (2) Volunteering & 1.56 & 0.98 & $1-4$ & 0.04 & 1.00 & & & & & & & & \\
\hline (3) Social \& Pol. Involv. & 1.91 & 0.68 & $1-4$ & 0.01 & 0.27 & 1.00 & & & & & & & \\
\hline (4) Care for Others & 3.13 & 0.56 & $1-4$ & 0.04 & 0.03 & 0.15 & 1.00 & & & & & & \\
\hline (5) Political Interest & 2.25 & 0.75 & $1-4$ & 0.05 & 0.18 & 0.43 & 0.06 & 1.00 & & & & & \\
\hline (6) Job Satisfaction & 7.05 & 1.92 & $0-10$ & 0.01 & 0.04 & 0.02 & 0.04 & 0.03 & 1.00 & & & & \\
\hline (7) Org. Tenure & 11.45 & 9.87 & $0-58.8$ & -0.03 & 0.09 & 0.03 & -0.03 & 0.09 & -0.01 & 1.00 & & & \\
\hline (8) Job Prestige & 60.29 & 25.75 & $30-207$ & 0.11 & 0.08 & 0.19 & 0.03 & 0.25 & 0.06 & 0.06 & 1.00 & & \\
\hline (9) Income (log) & 7.53 & 0.64 & $2.9-10.6$ & 0.21 & 0.10 & 0.08 & -0.05 & 0.23 & 0.13 & 0.20 & 0.31 & 1.00 & \\
\hline (10) Age & 40.09 & 10.50 & $17-86$ & -0.03 & 0.05 & 0.06 & -0.09 & 0.19 & -0.03 & 0.46 & 0.17 & 0.13 & 1.00 \\
\hline (11) Overtime (partly) paid & 0.32 & 0.46 & $0-1$ & 0.18 & 0.01 & -0.03 & 0.01 & -0.06 & 0.00 & -0.06 & -0.22 & 0.03 & -0.13 \\
\hline
\end{tabular}


Additionally, two socio-demographic measures are used. One is the respondents' income, which is expected to be positively associated with the employees' overtime (i.e., employees with more work responsibilities are more likely to do overtime) and, based on Hackl, Halla, and Pruckner (2007), also with volunteering intensity. Age was chosen as a second socio-demographic control because it is generally accepted in non-profit research that older people engage in volunteering activities more frequently (Tschirhart, 1998). Table 1 displays all descriptive information. To account for the panel structure of the data, the correlations were calculated for each wave separately and then averaged. The results from the table reveal that all variables are only moderately correlated.

\section{Methods}

To examine the stability and change of prosocial motivation across sectors, the study uses descriptive statistics, such as mean comparison across waves as well as the percentage of employees which changed or did not change their responses to the motivation questions (for a similar approach, see Rice \& Hilton, 1996). To investigate the causal effects of motivation on the two behaviors "doing overtime" and "volunteering," fixed-effects panel regression analysis is employed.

This study examines time-related variation, that is, how changes over time in an independent variable (prosocial motivation) affect changes in dependent variables (work behavior and volunteering), which is why fixed effects (FE) panel regressions are used. A strength of such FE regressions is that they - by fixing effects at the person-level - are able to account for many factors unique to an individual (even when unmeasured) that do not change across time. They use individuals as their own controls, disregard between-person variation, and partial-out time effects "within" individuals (Allison, 2005, p. 13; Wooldridge, 2010, p. 286). This is why this type of regression is known to deal well with omitted variable bias. Since FE panel regression focuses on variation across time, such models cannot identify effects for variables that are time-invariant (e.g., gender or, in this case, sector).

There are a few limitations one needs to acknowledge before the results of the study are presented. First, common-source bias can be an issue because all data were collected using the same survey instrument. Using FE panel regressions reduces this problem since the data consist of repeated survey responses and possible social desirability is likely to be eliminated because it might vary among individuals but rather remains constant across time. Second, "doing overtime" is admittedly a broad measure of prosocial work behavior in the public sector, as variation among tasks, occupations, and agencies can be expected; and some overtime might not be prosocial at all. However, the findings will show that there is a positive relationship between increases in "care for others" and employees' overtime, however, only in the public sector. This indicates that this work behavior is on average (despite possible within-sector variation) more prosocial in the public as compared to the private sector. Third, although the measures span 
across sixteen years, data is only available for four (respectively three) points in time, resulting in measurement gaps. However, due to the fact that there are no systematic trends, unmeasured increases and decreases in motivation between the observation points - if existent - are likely to have cancelled each other out. ${ }^{2}$

\section{Results and Discussion}

\section{Changes in Prosocial Motivation}

Figure 1 and 2 show the first descriptive findings regarding the two measures of prosocial motivation. As expected, the importance of prosocial motivation is higher in the public as compared to the private sector, but the differences in means are smaller than prior research has suggested. Although the $95 \%$ confidence intervals for each sector do not overlap for "social and political involvement," they do consistently overlap for "care for others." One plausible explanation is that both measures pick up on different aspects of prosocial motivation. Being in agreement with the statement that "social and political involvement is important" indicates the willingness to become active and do something. This seems to be more demanding than just stating broadly that "caring for others" is essential. This could be a reason why more people agreed with the latter item and why it thus discriminates less well between sectors. This would also explain the relatively large differences in the means between both variables.

Examining time trends, both figures do not provide evidence for much change in the measures of prosocial motivation, let alone, for sector-specific patterns. In fact, both measures seem to be largely constant over time which is also supported by the findings in table 2. Part A of that table shows that responses to the prosocial motivation questions remained largely consistent for a majority of employees when comparing two waves at a time, which also holds for the longest time span between two consecutive waves, 1995 and 2004. In addition, the stability of such motivation is on average greater for public compared to private sector employees.

\footnotetext{
${ }^{2}$ Another concern could be that employees switched sectors in-between the three measurement points $(1992,1995,2008)$ that were used in the regression analysis. A supplementary analysis shows, however, that only 46 [62] respondents had switched for a short period of time from the public [private] sector to the private [public] sector and back, and that the findings are robust to the exclusion of these employees.
} 
Figure 1: Importance of Social and Political Involvement across Sectors and Time

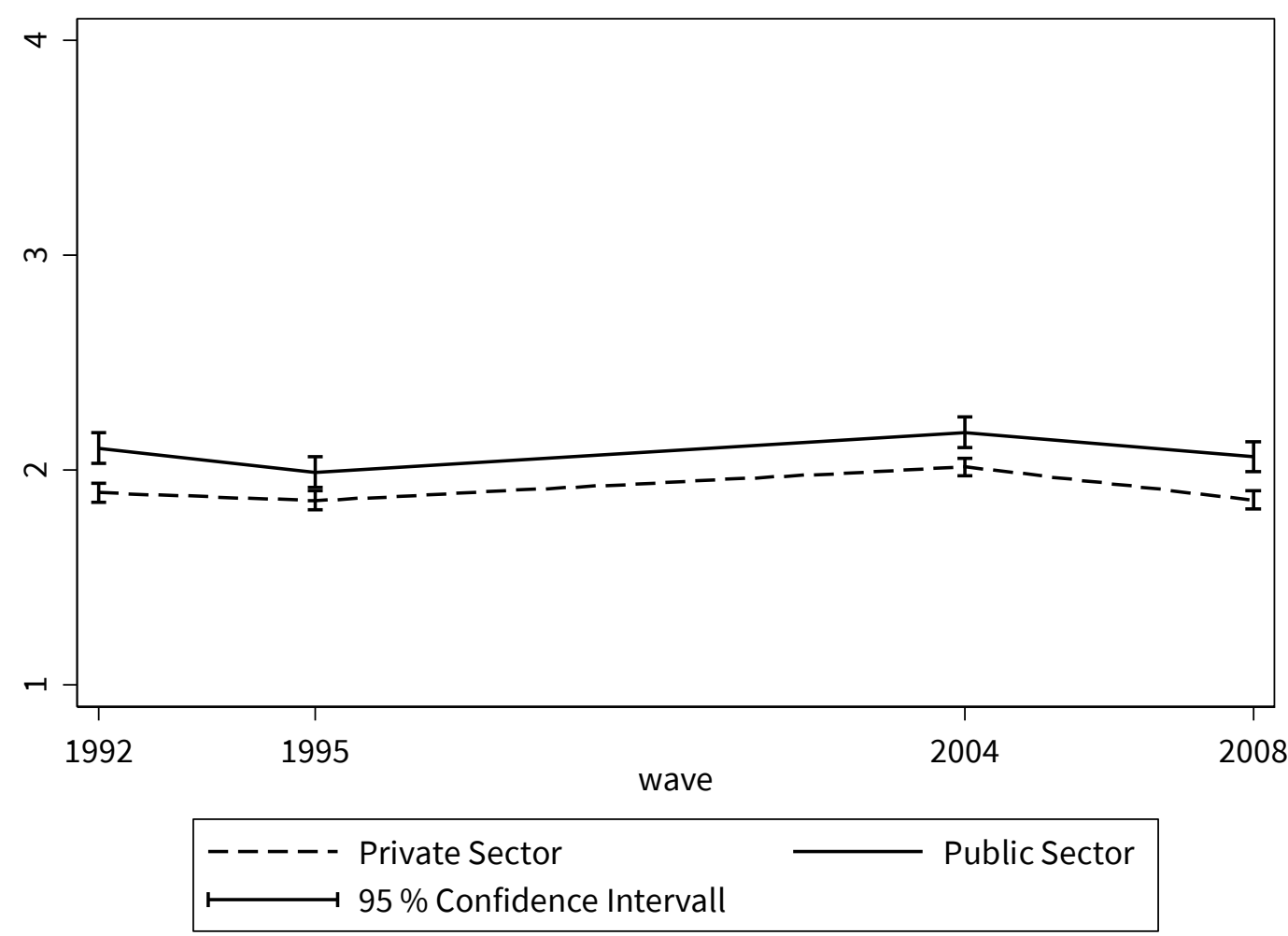

Figure 2: Care for Others across Sectors and Time

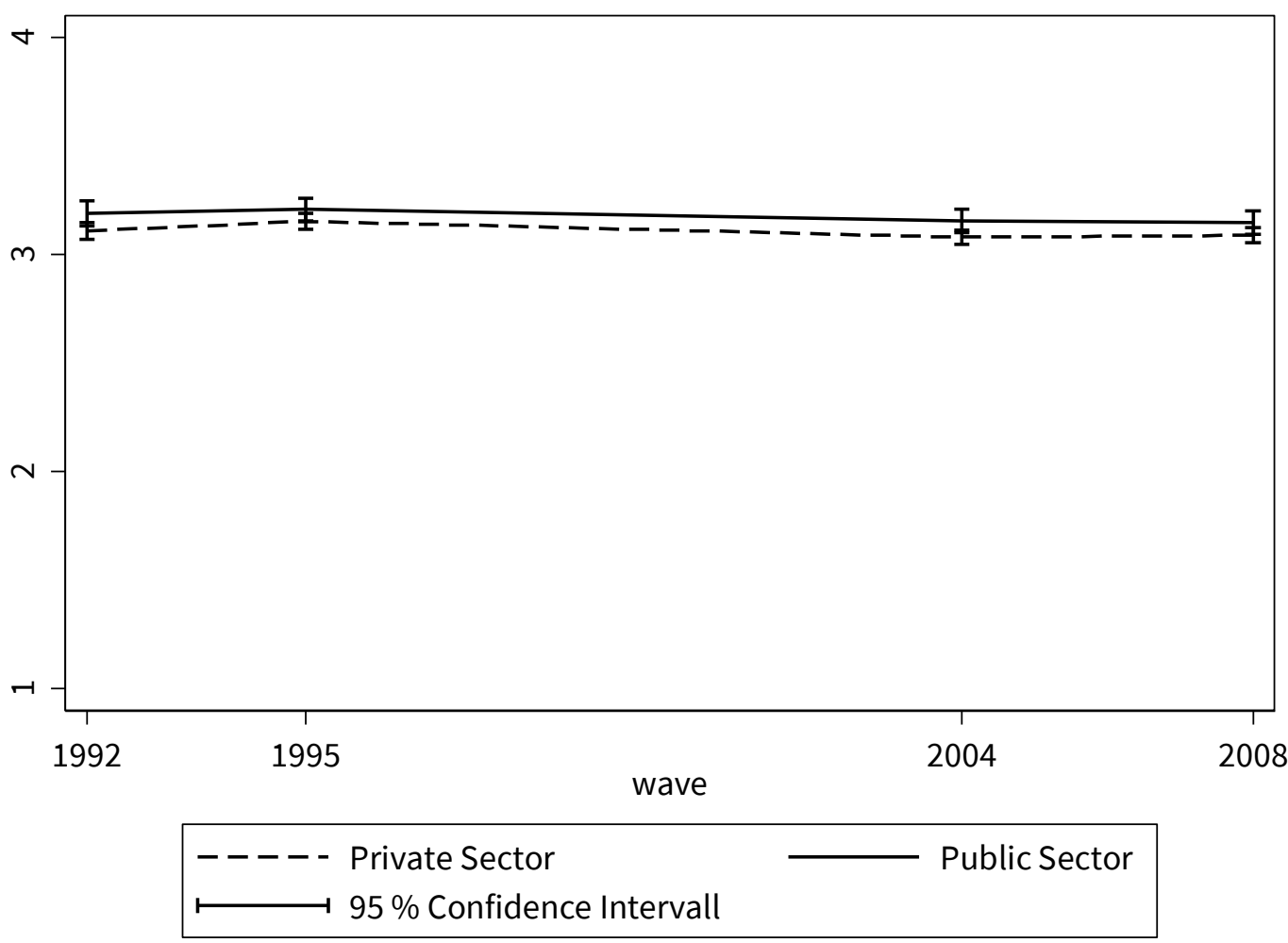


Part B provides a more detailed breakdown of the percentage of employees in each sector who moved or did not move up or down the 4-point Likert scales used to measure prosocial motivation. At a first glance, it may suggest that there has been more mobility (add up the percentages for all respondents who moved up or down by 1,2 , or $3+$ points) than stability, the latter ranging between $25 \%$ and $41 \%$. However, a closer look at the numbers indicates that more than half of all employees did not change their scores of prosocial motivation substantially. The one-point movers could be considered as evidence for stability or change, dependent on whether one considers a one-point move in 16 years as support for the former or the latter. However, the two-point movers provide a clearer picture: Across both items and sectors, between $89 \%$ and $94 \%$ of all employees who moved two Likert scale points returned back to their original response category, which supports the stability hypothesis.

Table 2: Stability and Change of Prosocial Attitudes

\begin{tabular}{lcccc}
\hline & \multicolumn{2}{c}{$\begin{array}{c}\text { Social \& Political In- } \\
\text { volvement }\end{array}$} & \multicolumn{2}{c}{ Care for Others } \\
& Private & Public & Private & Public \\
\hline Part A (in \%) & & & & \\
Stable 1992 and 1995 & 58.3 & 61.0 & 62.7 & 67.4 \\
Stable 1995 and 2004 & 56.7 & 56.3 & 62.5 & 67.7 \\
Stable 2004 and 2008 & 58.6 & 64.4 & 65.9 & 68.4 \\
Stable 1992 and 2008 & 51.5 & 59.8 & 60.3 & 65.6 \\
& & & & \\
Part B (in \%) & & & & \\
Stable & 25.3 & 32.1 & 35.8 & 40.6 \\
Absolute Movement = 1 & 33.1 & 26.5 & 27.9 & 27.4 \\
Absolute Movement = 2 & 27.1 & 28.0 & 26.1 & 26.2 \\
Absolute Movement = 3+ & 14.6 & 13.4 & 10.2 & 5.9 \\
\hline
\end{tabular}

The sample of this study is somewhat unique in that it only includes employees who have not switched sectors in a period of sixteen years. In order to check whether the findings are representative of employees more broadly, the study takes a more detailed look at the "sector switchers" - that is, employees who switched at least once from the private to the public sector (or vice versa) between two of the four observation points and who provided information on their prosocial motivation across all four waves $(n=267)$. It finds that these employees' prosocial attitudes are as stable as those of the original sample (results not reported but shown to the reviewers). After switching the sector, employees' prosocial values do not significantly go up or down but look a lot like the lines in figure 1. In fact, the switchers' motivation scores end up exactly between the public- and the private-sector lines, suggesting that these employees might constitute their own static hybrid type in-between the two sectors. These results do 
not change if employees who switched to the public sector are distinguished from those who switched to the private sector and if one examines the trends for both groups separately.

Overall, one sees little support for hypotheses 1-3. Instead, there is some validation of the null hypothesis that prosocial motivation is a stable trait rather than dynamic state, and that there are no evident socialization effects in either sector. This is intriguing as it contradicts previous studies, some of which were cross-sectional and examined variation in prosocial motivation as the dependent variable (Anderfuhren-Biget, 2012; Leisink \& Steijn, 2008; Moynihan \& Pandey, 2007; Wright et al., 2012), while others were longitudinal and observed shortterm change (Brænder \& Andersen, 2013; Kjeldsen \& Jacobsen, 2013; Ward, 2014). Although the findings of this study suggest that employees' prosocial motivation may be more stable than often expected, they are not entirely at odds with previous ones. The cross-sectional studies are likely to have picked up on selection and cohort effects in addition to socialization - and the impact of all three effects is difficult to disentangle without panel data (Vogel \& Kroll, 2016) - while the longitudinal studies suggest that change is possible if the interruption is significant enough and the time frame not long-term. The results are in line with some research from the area of sociology which has shown that comparable personal dispositions towards integration, minorities, or the role of government, once developed, only marginally change in an adult's life (Jennings \& Markus, 1984; Sears \& Funk, 1999).

\section{Behavioral Effects}

Table 3 provides the results for the effects of change in prosocial motivation on changes in volunteering and doing overtime. In the first two rows, the table shows the effects the main variables have on volunteering and overtime in the public sector. The third and fourth row display the results for the private sector. To make sure that increases in volunteering are not simply driven by decreases in workload (overtime) or vice versa, each of the models controls for the other dependent variable. For example, the first cell in model 1 shows the effect of the importance of social and political involvement on volunteering, while holding individuals' hours of overtime constant.

Hypotheses $4 \mathrm{a}$ and $4 \mathrm{~b}$ were concerned with whether increases in prosocial motivation of public sector employees will foster their engagement in both behaviors alike $\left(\mathrm{H}_{\mathrm{a}}\right)$ or only in one but not the other $\left(\mathrm{H}_{\mathrm{b}} \mathrm{b}\right)$. There is evidence in favor of the latter hypothesis, not the former. When looking at the public-sector subsample (model 1 and 2), one can see that increases in the importance of social and political involvement lead to increases in volunteering, but there is no effect on doing overtime, indicating that one behavior absorbs employees' prosocial motivation. With regard to the "care for others" variable, this can be seen even clearer. Here, increases in prosocial motivation lead to doing more overtime, while one's engagement in volunteering significantly declines. Based on the results, one cannot conclude that public employees would prefer volunteering over 
work behavior or vice versa, but the evidence indicates that prosocial motivation seems to be a limited resource which can get absorbed by either behavior.

There is also evidence in support of hypothesis 5: increases in prosocial motivation of private sector employees will foster their engagement in volunteering, not work behavior. These are average effects for the private sector, and although there are welfare-service related occupations in the private sector in which motivational change may affect work behavior, such occupations are the exception rather than the rule in the context of the German welfare state. Model 3 and 4 show that if scores of the importance of social and political involvement increase, people's overtime variable remains unaffected, while volunteering activities increase. Though one sees no effects of the care for others variable, table 3 portrays another interesting observation. If private-sector employees' political interest increases, a variable closely related to the concept of public service motivation (Ritz, 2011), they will do less overtime and instead more volunteering, which is additional support for the argument about behavioral choices.

The control variables also yield some interesting results which deserve to be acknowledged. Job satisfaction shows no significant effects whatsoever, suggesting that whether employees engage in volunteering activities outside of work or are doing less overtime has very little to do with how satisfied they are with their job. Job prestige, a measure that also tells us something about one's hierarchical position in an organization, is positively related with doing more overtime, however, only in the private sector. Another sector-specific effect can be found for the income variable. Higher salaries make private-sector employees do more work and less volunteering. The findings for age confirm prior research: older employees in both sectors are more likely to volunteer, but there are no effects on doing overtime. ${ }^{3}$

\footnotetext{
${ }^{3}$ It is interesting that age and tenure can have reversed effects on volunteering at least for the public sector sample. Although both variables are fairly collinear (except for years in which employees switch jobs), getting older makes it more likely to volunteer, while every additional year with the same agency decreases the odds of volunteering.
} 
Table 3: Fixed Effects Panel Regressions of Volunteering and Overtime

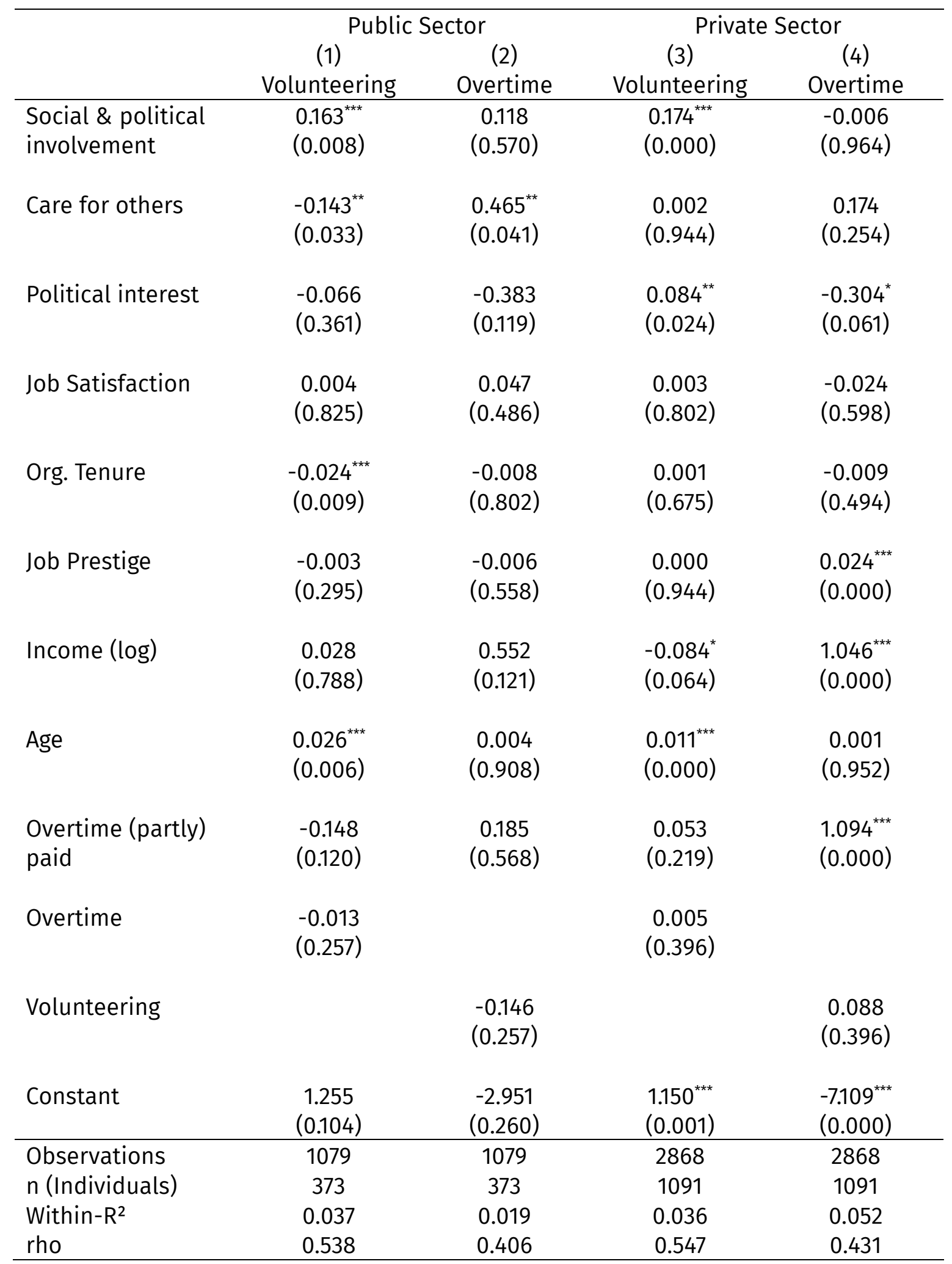

Note: Dummy variables to control for wave-specific effects are included but not reported; standardized beta coefficients; $p$-values in parentheses. ${ }^{*} p<.1,{ }^{* \star} p<.05,{ }^{* \star *} p<.01$ 


\section{Conclusion}

This article used panel data that covered a period of sixteen years to examine employees' prosocial motivation in the public and private sector, potential time trends, and their effects on volunteering and work behavior. It revealed that prosocial motivation is largely stable across time in both sectors, which is evidence against socialization effects. One also sees indications of motivation absorption: increases in employee's prosocial motivation will either lead to extra effort being put in their public service work or in volunteering activities after hours. There was no evidence that changes in prosocial motivation would trigger both behaviors simultaneously. The findings for private-sector employees were more straightforward (at least when assessed in aggregation rather than by occupation). Here, increases in prosocial motivation are likely to lead to more volunteering, not more engagement in work behavior.

The article contributes to a better conceptual understanding of prosocial motivation. It extends the findings by previous research that employees' prosocial motivation may change after taking on one's first job (Kjeldsen \& Jacobsen, 2013; Ward, 2014) or being deployed to combat (Brænder \& Andersen, 2013). Elaborating on this, the panel study presented here provides two additional insights. First, although research has shown that people's motivations do vary as a response to drastic changes in one's life, prosocial values might be more stable in the absence of such serious interruptions. Second, in the long run, several changes in motivation can cancel each other out, which is why the study finds relatively stable motivational averages for a period of 16 years. This also addresses the broader theoretical issue raised by Wright and Grant (2010) who asked whether prosocial motivation is a dynamic state or a static trait and whether the public sector attracts employees with strong social values and/or helps to enforce those through socialization. This study has mainly found evidence in support of the "stability" and the "attraction" hypotheses, though it has to be acknowledged that it was not possible to follow one cohort from the beginning of their career until the end.

A final theoretical insight from this article is that one can learn more about the behavioral effects of changes in prosocial motivation, behavioral choices, and the absorption of motivation. Prosocial motivation can trigger several prosocial behaviors, but it is also a "need" that loses some of its strength once it has found fulfillment through one outlet. Limited resources and capacity create choices for employees, so that increases in prosocial motivation across time might trigger related behaviors, however, at the risk of neglecting others. The article studied two particular behaviors, volunteering and doing overtime at one's public service job, and only found evidence for motivation absorption, not the triggering of both behaviors at the same time. Future research should elaborate on the findings of this study and contrast several work-related in-role and extra-role behaviors with each other. The study also emphasizes the great value of studying the short-term and long-term effects of specific managerial interventions (variations in leadership, autonomy, job en richment, or professional development) in addition to the comparison of average scores of prosocial motivation across 
time. Another interesting avenue would be to separate the samples by employee job tasks which exist across sectors and differentiate sector from occupational effects. This, however, would require large enough samples for comparable occupations within the two sectors.

The article can draw some conclusions for the practice of public management. From the finding that prosocial values only marginally vary across time as a function of socialization; one can infer that recruiting the "right" people is important. Recruiting a critical mass of people with a strong prosocial motivation might help to create a social norm in favor of related values and thus strengthen socialization effects. In order to do so, managers will need to emphasize such values in job listings and assessment centers and link them to their organization's mission in order to be able to attract this type of employee.

The findings of this study may also be a wakeup call for public managers. If prosocial motivation is absorbed by one activity and, as a result, loses its impact on another, then it needs to be treated as a scarce resource, and managers have to deliberately decide for what purposes they want to "make use" of it. If there is even a competition between realizing prosocial motivation at work or through volunteering, public organizations might lose critical motivational capital if their managers are not able to link employees' values to the mission of their organizations. This article finds support for such absorption effects, although evidence on its direction was mixed. In some cases, additional motivational capital will be invested in one's job. In other cases, however, prosocially driven public employees may rather focus on external opportunities to realize their motivation if they feel that their job does not allow them to have social impact. Looking at this from a work-life-balance perspective, it could be speculated that other-oriented employees will be the most satisfied when they can make a difference through their work and through volunteering. But such a hypothesis clearly calls for further research. 


\section{References}

Allison, P. D. (2005). Fixed effects regression methods for longitudinal data using SAS. Cary N.C: SAS Institute.

Anderfuhren-Biget, S. (2012). Profiles of Public Service-Motivated Civil Servants: Evidence from a Multicultural Country. International Journal of Public Administration, 35(1), 5-18. https://doi.org/10.1080/01900692.2011.635276

Andersen, L. B., Pallesen, T., \& Pedersen, L. H. (2011). Does Ownership Matter? Public Service Motivation Among Physiotherapists in the Private and Public Sectors in Denmark. Review of Public Personnel Administration, 31(1), 10-27. https://doi.org/10.1177/0734371X10394402

Bekkers, R. (2005). Participation in Voluntary Associations: Relations with Resources, Personality, and Political Values. Political Psychology, 26(3), 439-454. https://doi.org/10.1111/j.1467-9221.2005.00425.x

Bellé, N. (2013). Experimental Evidence on the Relationship between Public Service Motivation and Job Performance. Public Administration Review, 73(1), 143153. https://doi.org/10.1111/j.1540-6210.2012.02621.x

Brænder, M., \& Andersen, L. B. (2013). Does Deployment to War Affect Public Service Motivation? A Panel Study of Soldiers Before and After Their Service in Afghanistan. Public Administration Review, 73(3), 466-477. https://doi.org/10.1111/puar.12046

Bright, L. (2009). Why Do Public Employees Desire Intrinsic Nonmonetary Opportunities? Public Personnel Management, 38(3), 15-37. Retrieved from http://search.ebscohost.com/login.aspx?di-

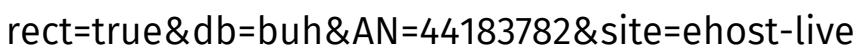

Christensen, R. K., \& Wright, B. E. (2011). The Effects of Public Service Motivation on Job Choice Decisions: Disentangling the Contributions of Person-Organization Fit and Person-Job Fit. Journal of Public Administration Research and Theory, 21(4), 723-743. https://doi.org/10.1093/jopart/muq085

Clerkin, R. M., Paynter, S. R., \& Taylor, J. K. (2009). Public Service Motivation in Undergraduate Giving and: Volunteering Decisions. American Review of Public Administration, 39(6), 675-698. https://doi.org/10.1177/0275074008327512

Cook, J. D., Hepworth, S. J., Wall, T. D., \& Warr, P. D. (1981). The Experience of work: A compendium and review of 249 measures and their use. Organizational and occupational psychology. London, New York: Academic Press.

Coursey, D., Brudney, J. L., Littlepage, L., \& Perry, J. L. (2011). Does Public Service Motivation Matter in Volunteering Domain Choices? A Test of Functional Theory. Review of Public Personnel Administration, 31(1), 48-66. https://doi.org/10.1177/0734371X10394405 
Dormann, C., \& Zapf, D. (2001). Job satisfaction: a meta-analysis of stabilities. Journal of Organizational Behavior, 22(5), 483-504. https://doi.org/10.1002/job.98

Frey, B. S., \& Jegen, R. (2001). Motivation Crowding Theory. Journal of Economic Surveys, 15(5), 589-611. https://doi.org/10.1111/1467-6419.00150

Frietsch, R., \& Wirth, H. (2001). Die Übertragung der Magnitude-Prestigeskala von Wegener auf die Klassifikation der Berufe. ZUMA Nachrichten, 25(48), 139-165.

Gagné, M., \& Deci, E. L. (2005). Self-determination theory and work motivation. Journal of Organizational Behavior, 26(4), 331-362. https://doi.org/10.1002/job.322

Grant, A. M. (2008). Does intrinsic motivation fuel the prosocial fire? Motivational synergy in predicting persistence, performance, and productivity. Journal of Applied Psychology, 93(1), 48-58. https://doi.org/10.1037/0021-9010.93.1.48

Grant, A. M., \& Ashford, S. J. (2008). The dynamics of proactivity at work. Research in Organizational Behavior, 3-34. https://doi.org/10.1016/j.riob.2008.04.002

Hackl, F., Halla, M., \& Pruckner, G. J. (2007). Volunteering and Income? The Fallacy of the Good Samaritan? Kyklos, 60(1), 77-104. https://doi.org/10.1111/j.14676435.2007.00360.x

Hatemi, P. K., Funk, C. L., Medland, S. E., Maes, H. M., Silberg, J. L., Martin, N. G., \& Eaves, L. J. (2009). Genetic and Environmental Transmission of Political Attitudes Over a Life Time. The Journal of Politics, 71(03), 1141. https://doi.org/10.1017/S0022381609090938

Jacobsen, C. B., Hvitved, J., \& Andersen, L. B. (2014). Command and motivation: How the perception of external interventions relates to intrinsic motivation and public service motivation. Public Administration, 92(4), 790-806. https://doi.org/10.1111/padm.12024

Jennings, M. K., \& Markus, G. B. (1984). Partisan Orientations over the Long Haul: Results from the Three-Wave Political Socialization Panel Study. The American Political Science Review, 78(4), 1000-1018. https://doi.org/10.2307/1955804

Kim, S., Vandenabeele, W., Wright, B. E., Andersen, L. B., Cerase, F. P., Christensen, R. K.,. . . Vivo, P. de. (2013). Investigating the Structure and Meaning of Public Service Motivation across Populations: Developing an International Instrument and Addressing Issues of Measurement Invariance. Journal of Public Administration Research and Theory, 23(1), 79-102. https://doi.org/10.1093/jopart/mus027

Kjeldsen, A. M. (2014). Dynamics of Public Service Motivation: Attraction-Selection and Socialization in the Production and Regulation of Social Services. Public Administration Review, 74(1), 101-112. https://doi.org/10.1111/puar.12154 
Kjeldsen, A. M., \& Jacobsen, C. B. (2013). Public Service Motivation and Employment Sector: Attraction or Socialization? Journal of Public Administration Research and Theory, 23(4), 899-926. https://doi.org/10.1093/jopart/mus039

Kroll, A., \& Vogel, D. (2014). The PSM-Leadership Fit: A model of performance information use. Public Administration, 92(4), 974-991. https://doi.org/10.1111/padm.12014

Lee, Y.-j. (2011). Behavioral Implications of Public Service Motivation: Volunteering by Public and Nonprofit Employees. American Review of Public Administration, 42(1), 104-121. https://doi.org/10.1177/0275074011398120

Leisink, P., \& Steijn, B. (2008). Recruitment, Attraction, and Selection. In J. L. Perry \& A. Hondeghem (Eds.), Motivation in Public Management: The call of Public Service (pp. 118-135). Oxford: Oxford University Press.

Leisink, P., \& Steijn, B. (2009). Public service motivation and job performance of public sector employees in the Netherlands. International Review of Administrative Sciences, 75(1), 35-52.

Lewis, G. B., \& Frank, S. A. (2002). Who Wants to Work for the Government? Public Administration Review, 62(4), 395-404. https://doi.org/10.1111/0033-3352.00193

MacKenzie, S. B., Podsakoff, P. M., \& Ahearne, M. (1998). Some Possible Antecedents and Consequences of In-Role and Extra-Role Salesperson Performance. Journal of Marketing, 62(3), 87. https://doi.org/10.2307/1251745

Mortimer, J. T., \& Lorence, J. (1979). Work Experience and Occupational Value Socialization: A Longitudinal Study. The American Journal of Sociology, 84(6), 1361-1385.

Moynihan, D. P., \& Pandey, S. K. (2007). The Role of Organizations in Fostering Public Service Motivation. Public Administration Review, 67(1), 40-53. https://doi.org/10.1111/j.1540-6210.2006.00695.x

Moynihan, D. P., \& Pandey, S. K. (2008). The Ties that Bind: Social Networks, Person-Organization Value Fit, and Turnover Intention. Journal of Public Administration Research and Theory, 18(2), 205-227. https://doi.org/10.1093/jopart/mum013

Pandey, S. K., \& Stazyk, E. C. (2008). Antecedents and Correlates of Public Service Motivation. In J. L. Perry \& A. Hondeghem (Eds.), Motivation in Public Management: The call of Public Service (pp. 101-117). Oxford: Oxford University Press.

Pandey, S. K., Wright, B. E., \& Moynihan, D. P. (2008). Public Service Motivation and Interpersonal Citizenship Behavior in Public Organizations: Testing a Preliminary Model. International Public Management Journal, 11(1), 89-108. https://doi.org/10.1080/10967490801887947

Perry, J. L. (1996). Measuring Public Service Motivation: An Assessment of Construct Reliability and Validity. Journal of Public Administration Research and Theory, 6(1), 5-22. 
Perry, J. L., Brudney, J. L., Coursey, D. H., \& Littlepage, L. (2008). What Drives Morally Committed Citizens? A Study of the Antecedents of Public Service Motivation. Public Administration Review, 68(3), 445-458. https://doi.org/10.1111/j.15406210.2008.00881.x

Perry, J. L., Hondeghem, A., \& Wise, L. R. (2010). Revisiting the Motivational Bases of Public Service: Twenty Years of Research and an Agenda for the Future. Public Administration Review, 70(5), 681-690. https://doi.org/10.1111/j.15406210.2010.02196.x

Perry, J. L., \& Wise, L. R. (1990). The Motivational Bases of Public Service. Public Administration Review, 50(3), 367-373. https://doi.org/10.2307/976618

Rainey, H. G. (1982). Reward Preferences among Public and Private Managers: In Search of the Service Ethic. American Review of Public Administration, 16(4), 288-302. https://doi.org/10.1177/027507408201600402

Rice, T. W., \& Hilton, T. A. (1996). Partisanship over Time: A Comparison of United States Panel Data. Political Research Quarterly, 49(1), 191-201.

Ritz, A. (2011). Attraction to public policy-making: A qualitative inquiry into improvements in PSM measurement. Public Administration, 89(3), 1128-1147. https://doi.org/10.1111/j.1467-9299.2011.01923.x

Sears, D., \& Funk, C. (1999). Evidence of the Long-Term Persistence of Adults' Political Predispositions. Journal of Politics, 61(1), 1-28.

Simon, H. A. (1959). Theories of Decision-Making in Economics and Behavioral Science. The American Economic Review, 49(3), 253-283. https://doi.org/10.2307/1809901

Steijn, B. (2008). Person-Environment Fit and Public Service Motivation. International Public Management Journal, 11(1), 13-27.

Tschirhart, M. (1998). Understanding the Older Stipended Volunteer: Age-Related Differences among AmeriCorps Members. Public Productivity \& Management Review, 22(1), 35-48. https://doi.org/10.2307/3380588

Vandenabeele, W. (2009). The mediating effect of job satisfaction and organizational commitment on self-reported performance. International Review of Administrative Sciences, 75(1), 11-34. https://doi.org/10.1177/0020852308099504

Vogel, D., \& Kroll, A. (2016). The Stability and Change of PSM-related Values across Time: Testing Theoretical Expectations against Panel Data. International Public Management Journal, 19(1), 53-77. https://doi.org/10.1080/10967494.2015.1047544

Wagner, G. G., Frick, J. R., \& Schupp, J. (2007). The German Socio-Economic Panel Study (SOEP) - Scope, Evolution and Enhancements. Journal of Applied Social Science Studies (Schmollers Jahrbuch), 127, 139-169.

Ward, K. D. (2014). Cultivating Public Service Motivation through AmeriCorps Service: A Longitudinal Study. Public Administration Review, 74(1), 114-125. https://doi.org/10.1111/puar.12155 
Wegener, B. (1992). Concepts and measurement of prestige. Annual review of sociology, 18(1), 253-280.

Wooldridge, J. M. (2010). Econometric analysis of cross section and panel data (2nd ed.). Cambridge, Mass: MIT Press.

Wright, B. E. (2007). Public Service and Motivation: Does Mission Matter? Public Administration Review, 67(1), 54-64. https://doi.org/10.1111/j.15406210.2006.00696.x

Wright, B. E., \& Christensen, R. K. (2010). Public Service Motivation: A Test of the Job Attraction-Selection-Attrition Model. International Public Management Journal, 13(2), 155-176.

Wright, B. E., Christensen, R. K., \& Pandey, S. K. (2013). Measuring Public Service Motivation: Exploring the Equivalence of Existing Global Measures. International Public Management Journal, 16(2), 197-223. https://doi.org/10.1080/10967494.2013.817242

Wright, B. E., \& Grant, A. M. (2010). Unanswered Questions about Public Service Motivation: Designing Research to Address Key Issues of Emergence and Effects. Public Administration Review, 70(5), 691-700.

Wright, B. E., Moynihan, D. P., \& Pandey, S. K. (2012). Pulling the Levers: Transformational Leadership, Public Service Motivation, and Mission Valence. Public Administration Review, 72(2), 206-215. https://doi.org/10.1111/j.15406210.2011.02496.x 


\section{Appendix: Measures}

\begin{tabular}{|c|c|}
\hline Variable & Operationalization \\
\hline Overtime & Overtime in hours per week \\
\hline Volunteering & $\begin{array}{l}\text { Now some questions about your free-time. Please indicate } \\
\text { how often you take part in each activity ... } \\
\ldots \text {.. Volunteering in clubs, associations or social services ( } 4 \text { = } \\
\text { at least once a week; } 3 \text { = at least once a month; } 2 \text { = seldom; } \\
1 \text { = never) }\end{array}$ \\
\hline $\begin{array}{l}\text { Importance of } \\
\text { Social \& Political } \\
\text { Involvement }\end{array}$ & $\begin{array}{l}\text { Various things can be important for various people. Are the } \\
\text { following things ... currently ... for you? } \\
\text {...to be politically and/or socially involved } \\
\text { ( } 1 \text { = not at all important; } 4 \text { = very important) }\end{array}$ \\
\hline Care for Others & $\begin{array}{l}\text { Various things can be important for various people. Are the } \\
\text { following things ... currently ... for you? } \\
\text {...to be there for others } \\
(1=\text { not at all important; } 4 \text { = very important) }\end{array}$ \\
\hline Political Interest & $\begin{array}{l}\text { Generally speaking, how much are you interested in poli- } \\
\text { tics? } \\
\text { ( } 1 \text { = not at all; } 4 \text { = very much) }\end{array}$ \\
\hline Job Satisfaction & $\begin{array}{l}\text { How satisfied are you today with the following areas of } \\
\text { your life...? } \\
\ldots \text { with your job? } \\
(0=\text { totally unhappy; } 10=\text { totally happy) }\end{array}$ \\
\hline $\begin{array}{l}\text { Organizational } \\
\text { Tenure }\end{array}$ & $\begin{array}{l}\text { When did you start your current position? } \\
\text { [answer was subtracted from wave] }\end{array}$ \\
\hline Job Prestige & $\begin{array}{l}\text { Value on the Magnitude Prestige Scale (Wegener, 1992). } \\
\text { Value is assigned based on the German Federal Statistical } \\
\text { Office's occupational classification of } 1992 \text { (KLAS). The pro- } \\
\text { cedure has been documented in Frietsch and Wirth (2001) }\end{array}$ \\
\hline $\log ($ Income $)$ & $\begin{array}{l}\text { How high was your income from employment last month } \\
\text { (gross)? }\end{array}$ \\
\hline Age & [wave] - [year of birth] \\
\hline $\begin{array}{l}\text { Overtime } \\
\text { (partly) paid }\end{array}$ & $\begin{array}{l}\text { If you do work overtime, is the work paid, compensated } \\
\text { with time-off, or not compensated at all? } \\
\text { ( } 0 \text { = not compensated at all, compensated with time-off, no } \\
\text { overtime; } 1 \text { = paid, partly paid/partly compensated with } \\
\text { time-off) }\end{array}$ \\
\hline
\end{tabular}

